\title{
Targeted exon sequencing fails to identify rare coding variants with large effect in rheumatoid arthritis
}

So-Young Bang ${ }^{1}$, Young-Ji Na', Kwangwoo Kim', Young Bin Joo', Youngho Park², Jaemoon Lee ${ }^{2}$, Sun-Young Lee ${ }^{3}$, Adnan A Ansari ${ }^{3}$, Junghee Jung ${ }^{4}$, Hwanseok Rhee", Jong-Young Lee ${ }^{5}$, Bok-Ghee Han ${ }^{5}$, Sung-Min Ahn ${ }^{3,6}$,

Sungho Won ${ }^{7}$, Hye-Soon Lee ${ }^{1 *}$ and Sang-Cheol Bae ${ }^{1 *}$

\begin{abstract}
Introduction: Although it has been suggested that rare coding variants could explain the substantial missing heritability, very few sequencing studies have been performed in rheumatoid arthritis (RA). We aimed to identify novel functional variants with rare to low frequency using targeted exon sequencing of RA in Korea.

Methods: We analyzed targeted exon sequencing data of 398 genes selected from a multifaceted approach in Korean RA patients $(n=1,217)$ and controls $(n=717)$. We conducted a single-marker association test and a gene-based analysis of rare variants. For meta-analysis or enrichment tests, we also used ethnically matched independent samples of Korean genome-wide association studies (GWAS) $(n=4,799)$ or immunochip data $(n=4,722)$.

Results: After stringent quality control, we analyzed 10,588 variants of 398 genes from 1,934 Korean RA case controls. We identified 13 nonsynonymous variants with nominal association in single-variant association tests. In a meta-analysis, we did not find any novel variant with genome-wide significance for RA risk. Using a gene-based approach, we identified 17 genes with nominal burden signals. Among them, VSTM1 showed the greatest association with RA $\left(P=7.80 \times 10^{-4}\right)$. In the enrichment test using Korean GWAS, although the significant signal appeared to be driven by total genic variants, we found no evidence for enriched association of coding variants only with RA.
\end{abstract}

Conclusions: We were unable to identify rare coding variants with large effect to explain the missing heritability for RA in the current targeted resequencing study. Our study raises skepticism about exon sequencing of targeted genes for complex diseases like RA.

\section{Introduction}

Rheumatoid arthritis (RA (MIM 180300)) is a complex autoimmune disorder that results from both genetic and environmental risk factors $[1,2]$. Strong evidence regarding the existence of a genetic predisposition for RA has been supported by several familial studies including twin studies, in which the heritability of RA has been estimated to be approximately $65 \%[1,2]$.

Nearly 60 RA risk loci were identified in several large studies including genome-wide association studies (GWAS) [3-6] and immunochip (iCHIP) $[7,8]$ arrays using common

\footnotetext{
* Correspondence: Ihsberon@hanyang.ac.kr; scbae@hanyang.ac.kr 'Department of Rheumatology, Hanyang University Hospital for Rheumatic Diseases, 220 Wangsimni-ro, Seoul 133-792, Republic of Korea Full list of author information is available at the end of the article
}

single nucleotide variants (SNVs). The largest genetic contribution effect size has been identified for the major histocompatibility complex (MHC) locus with evidence for three independent association signals on $H L A-B$, $H L A-D R B 1$, and $H L A-D P B 1$ affecting five amino acid positions $[9,10]$. The total variance of the MHC region explained $13.03 \%$ of the RA risk [11]. The other nonMHC genes identified were primarily immune pathway genes, though their effect sizes were quite modest. To date, the known RA risk loci can explain only about $25 \%$ of the total genetic heritability [12].

It has been suggested that rare or low-frequency variants could explain the substantial unexplained heritability of many complex diseases, most of which were not fully captured using the previous conventional genotyping 
technology. Recently, Stahl et al. [11] inferred a highly polygenic model that attempted to explain the missing heritability of RA. In this model, it was suggested that a small number of rare variants with large effect sizes may contribute to heritability in addition to hundreds of common variants.

New genomic technologies, including next-generation sequencing (NGS), can provide a new approach for identification of rare variants. With advances in NGS technology, the role of rare or low-frequency variants in many complex diseases like RA can be investigated to better characterize the genetic architecture of the disease. Recently, several sequencing studies that have investigated common autoimmune diseases have shown that rare variants within genes containing common variants are associated with complex diseases [13-16]. For RA, Diogo et al. [17] performed deep exon sequencing of 25 biological candidate genes discovered by GWASs in 500 RA cases and 650 controls of European ancestry and subsequent dense genotyping in larger samples, in which they found accumulation of a few rare nonsynonymous variants with nominal significance instead of variants with large effect of genome-wide significance.

Here, we aimed to identify novel functional variants with rare to low frequency using targeted exon sequencing in Korean RA, which dealt with hundreds of selected genes that were related to RA in various aspects such as previous identified genes from GWASs and immunochip data, literature reviews, and related pathways.

\section{Materials and methods Patients and controls}

A total of 1,252 RA cases were enrolled from the BAE cohort of Hanyang University Hospital for Rheumatic Diseases and satisfied the American College of Rheumatology 1987 classification criteria [18] for RA. The ethnically matched 745 healthy controls, excluding those with a personal or familial history of any autoimmune disease, were recruited at the same institute. Informed consent was obtained from all individuals via a questionnaire at the time of enrollment, when clinical information was also collected. The study was approved by the institutional review board of Hanyang University (HYG-11-015-1).

\section{Targeted gene selection}

We selected candidate genes using a comprehensive approach that included previous genetic and biological research, pathway databases, text-mining analysis, and animal-model databases (Figure S1 in Additional file 1). Of the non-MHC candidate genes, we included (a) 106 known RA risk loci identified via literature review $[3,4,6,9,19]$, (b) 519 genes associated with RA in our Korean iChip dataset [8], (c) 155 genes shared by both RA and systemic lupus erythematosus (SLE) in our previous Korean GWAS datasets [4,20], (d) 18 genes in RA-related pathways, (e) 65 genes identified via text mining using GRAIL from recent GWAS data $[3,4]$, and (f) 8 human homologs of mouse genes that induced an RA-like phenotype from the Mouse Genome Database (MGD) [21]. Altogether, 666 designable target genes were selected for exon sequencing.

\section{Exon sequencing}

We enriched the target exons with Agilent's SureSelect capture kit (target region $=1.36 \mathrm{Mb}$ ) and performed highthroughput paired-end sequencing using a HiSeq2000 (Agilent Technologies, Santa Clara, CA, USA). The sequencing reads were mapped to the human reference genome, where the reference sequence was UCSC assembly hg19 (NCBI build 37.1) using Burrows-Wheeler Aligner (BWA) software [22]. We then applied programs packaged in Picard-tools in order to convert the previous SAM file into a format that was sorted by mapping coordinates and to remove PCR duplicates. We created another SAM file that included only reads that uniquely mapped to the reference genome, and transformed this into a BAM file using Samtools [23]. Those variants are annotated by ANNOVAR (Figure S2 in Additional file 1).

We then performed stringent quality control for 666 target gene by which we selected only high coverage genes that were sequenced coding-region based on the public database (db). We obtained an initial dataset with 50,247 variants from 666 targeted genes. We filtered the original genotype matrix by single nucleotide polymorphism (SNP) quality and depth coverage. The filtered genotype data contains genotype calls satisfying with practical guidance in rare variants analysis of complex trait association studies [24]; coding sites sequenced with $>20 \times$ coverage and quality score $>30$ in at least $80 \%$ of cases and controls in the public database $(\mathrm{db})$ or in the designed targeting genes. As a result, a total of 398 genes (mean 92.0\% coverage of the captured exon) in 1,997 individuals were used in the subsequent variant-calling analysis (Table S1 in Additional file 1). When we called the variants if SNVs had minimal depth coverage $>20 \times$ and a quality score $>30$ in more than $80 \%$ of the subjects sequenced, a total of 12,916 variants within 398 genes were identified. We then eliminated SNVs that had insufficient call rates $(<90 \%)$ in cases and controls, Hardy-Weinberg disequilibrium with $P<0.01$ in controls, and also eliminated samples that had insufficient call rates $(<90 \%)$. We finally analyzed the 10,588 exonic variants of 1,934 samples for further single-variant association test, genebased test, and pathway-based association enrichment test (Table 1, Table S2 in Additional file 1). There was no evidence of skewed genotyping between cases and controls in the principle component (PC) analysis (Figure S3 in Additional file 1). 


\begin{tabular}{|c|c|c|}
\hline & $\begin{array}{l}\text { RA cases } \\
(n=1,217)^{*}\end{array}$ & $\begin{array}{l}\text { Controls } \\
(\mathrm{n}=717)^{*}\end{array}$ \\
\hline Age of onset (mean $\pm S D$ years) & $41.9 \pm 12.8$ & $35.1 \pm 10.7$ \\
\hline Disease duration (mean \pm SD years) & $9.9 \pm 11.1$ & - \\
\hline Female (\%) & 87.4 & 85.3 \\
\hline Rheumatoid factor (\%) & 97.8 & - \\
\hline $\begin{array}{l}\text { Anti-cyclic citrullinated peptide } \\
\text { autoantibodies (\%) }\end{array}$ & 98.1 & - \\
\hline
\end{tabular}

"Cryptic relatedness with duplicate or first-degree relatives using KING software, outlier (deviating $>8$ SEM on any of the five principal components), or samples with less than $80 \%$ of the data sequenced were removed. A total of 1,934 samples were included for further analysis. SD, standard deviation; SEM, standard error of the mean.

\section{Statistical analysis}

To analyze for single-marker association with RA in targeted exon sequencing data, odds ratios (OR) and $P$ values were calculated using PLINK v1.07 software [25] with adjustments for the top 10 PCs in logistic regression. Fisher's exact tests were also used for association tests of each rare variant.

For a meta-analysis (3,580 RA cases and 7,938 controls) using a Korean RA GWAS [4] and iCHIP [8] data generated from ethnically matched independent sample collections in addition to the current NGS results, we applied several quality-control filters on Korean RA GWAS ( $\mathrm{n}=4,799)$ and iCHIP $(\mathrm{n}=4,722)$ data to select highquality SNVs (minor allele frequency $(\mathrm{MAF}) \geq 1 \%, P$ value of Hardy-Weinberg equilibrium (HWE) $<10^{-4}$ and call rate $>95 \%$ in cases and controls).

For an enrichment test for exonic SNPs in 77 newly identified genes $(P<0.05$ in a single-variant test of sequencing data), we imputed common and low-frequency variants (MAF $>0.5 \%$ ) from the Korean GWAS data $(800$ RA cases and 3,999 controls) by ShapeIt and IMPUTE2 with the 1000 Genomes Phase I reference panel. We performed logistic regressions for 1,000-times permuted phenotypes with the top $10 \mathrm{PCs}$ as covariates by PLINK. Then, the numbers of genic, exonic, nonsynonymous, or synonymous variants reaching the $P_{\text {threshold }}<0.05$ between observed and permuted data were compared by using a Fisher's exact test.

In a gene-based analysis of rare coding variants (MAF <5\%), we performed both nonburden testing (optimal sequence kernel association test (SKAT-O)) [26] and burden testing (SCORE-seq) $[27,28]$. Weighted analysis was performed for rare nonsynonymous variants using SIFT [29], PolyPhen2 [30], and CAROL [31] scores. Statistical significance was determined by using $1,000,000$ case-control permutations.

In pathway-based enrichment test of NGS data, we generated 1,000 permuted phenotype sets and their disease association $P$ values for each SNV by logistic regression with adjustment for the top 10 PCs. To eliminate linkage disequilibrium (LD)-derived enrichment bias, we clumped the set of SNVs $\left(r^{2}<0.4\right)$ in order of statistical significance. Then, we compared the number of SNV with $P<P_{\text {threshold }}$ between permuted datasets and empirical datasets by Fisher's exact tests. Genes in each functional pathway were obtained from Ontology and KEGG.

\section{Ethics approval}

Ethics approval was granted by the institutional ethics committee of Hanyang University in the Republic of Korea.

Patient and control consents were obtained.

\section{Results}

After stringent quality control on the 666 targeted genes (Figure S1 in Additional file 1) as well as the sequenced samples (see Materials and Methods), we obtained a final dataset for analysis that consisted of 10,588 exonic variants from 398 genes in 1,217 RA cases (age $=41.9 \pm 12.8$ (mean age \pm standard deviation (SD)); female $=87.4 \%$ ) and 717 controls (age $=35.1 \pm 10.7$ (mean age \pm SD); female $=85.3 \%)($ Table 1$)$.

The majority of SNVs were rare $(90.6 \%$ with MAF <5\%), and 6,605 SNVs were novel which were not identified in the 1000 Genome Project dataset (Figure S4 in Additional file 1). The transition/transversion ( $\mathrm{Ti} / \mathrm{Tv}$ ) rate was 2.93 in RA cases and 2.92 in controls, which indicates good quality control based on expected human mutation types (Table $\mathrm{S} 2$ in Additional file 1). We note that a high concordance rate was observed between genotype calls from sequencing versus other genotyping methods such as GWAS and iCHIP by non-reference sensitivity [32] and non-reference discrepancy rate [33] (Table S3 in Additional file 1). In addition, validation using a TaqMan assay for a selected 37 SNVs showed high concordance rates with sequencing data (99.3\%).

We used three different strategies for analysis of variants that passed the stringent quality control: (1) single-variant association test, (2) gene-based test for rare variants of which MAF are less than 0.05, and (3) pathway-based association enrichment test (Figure 1). Regarding the single-variant association test, we further perform a meta-analysis using the current NGS data and previous GWAS/iCHIP data from independent Koreans, and evaluate that exonic SNPs in the genes associated with RA in the NGS data are enriched for RA association in imputed GWAS dataset.

In the first single-variant association analysis using 10,588 SNVs in 1,217 cases and 717 controls, we identified thirteen nonsynonymous variants with $P<0.01$, none of which reached the significance threshold after Bonferroni correction (Table S4 in Additional file 1). To compensate for the limited power that may have resulted in a lack of significant associations, we performed a 


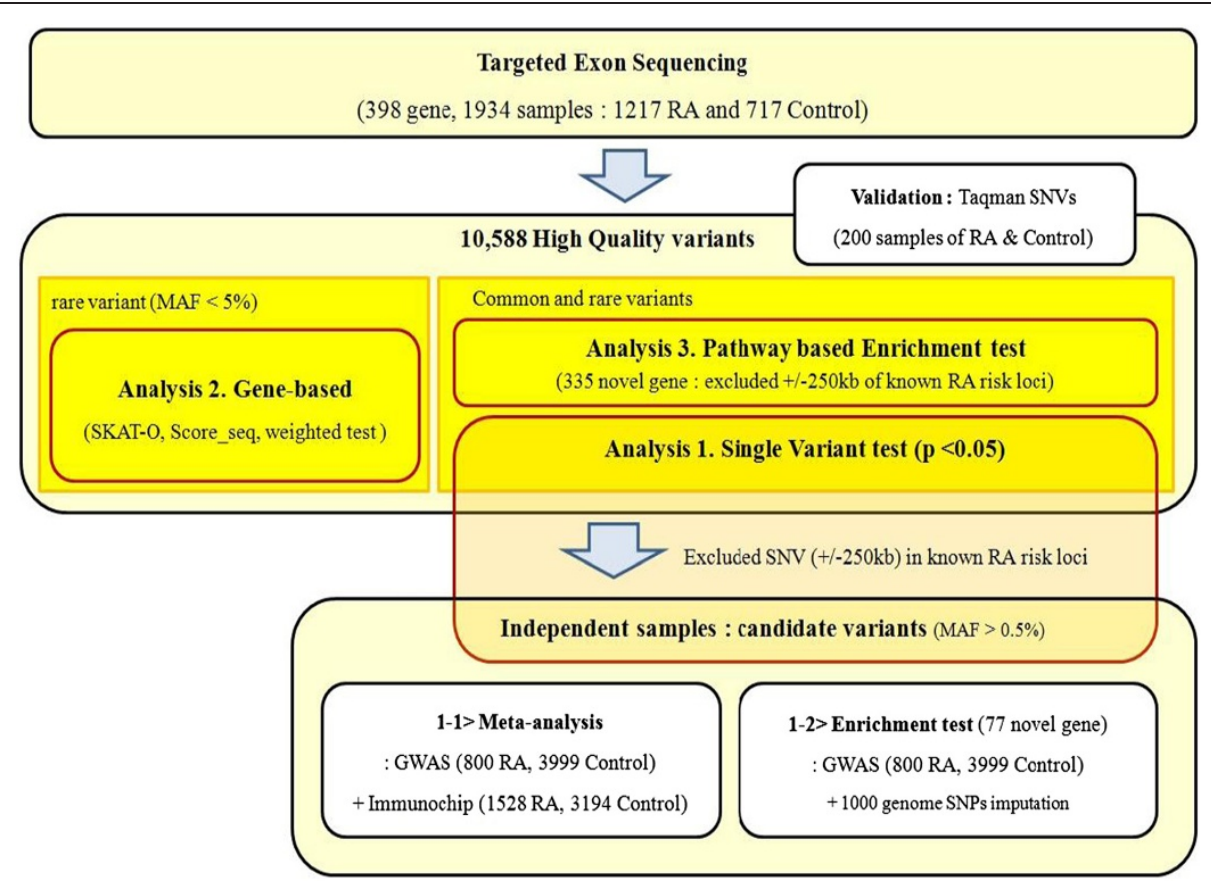

Figure 1 Description of the study design. We analyzed data from protein-coding variants within targeted genes using three different strategies for analysis.

meta-analysis for 108 coding SNVs (located in 89 genes) that were associated with a $P$ value less than 0.05 in the single-variant association test. We used two independent Korean genomic data in the meta-analysis with NGS data; one was Korean RA GWAS dataset [4] $(\mathrm{n}=1,099)$ combined with independent Korean control data $(n=3,700)$ genotyped by Illumina HumanOmni1-Quad BeadChip, and the other was Korean iCHIP data from 4,722 independent case-control subjects [8].

We focused on novel genes in the meta-analysis dataset of 3,580 RA cases and 7,938 controls, excluding any known GWAS or iCHIP signals. However, neither common nor low-frequency novel variants achieved genome-wide significance $\left(P<1.0 \times 10^{-8}\right)$, with an SNV (rs1088680) within PRKCH showing the strongest association $\left(P=3.16 \times 10^{-5}\right)$ (Table S5 in Additional file 1$)$.

Next, in an attempt to investigate whether an aggregate effect of 89 risk genes identified in NGS $(P<0.05)$ exists or not, we performed an enrichment analysis for RA associations in all risk genes excluding 12 known RA risk loci using an independent dataset from our GWAS. Association of 41,454 SNVs within the 77 genes in the imputed Korean GWAS data was compared with the results after 1,000 case-control permutations by Fisher's exact tests (Figure 2). To eliminate LD-derived bias, we clumped the set of independent SNVs $\left(r^{2}<0.4\right)$.

Although the significant signal appeared to be driven by 4,376 genic variants (observed $\mathrm{N}_{\mathrm{P}<P \text { threshold }} / \mathrm{N}_{\text {total }}=$ $386 / 4376 ; P_{\text {enrichment }(\text { genic) }}=1.04 \times 10^{-32}$ ), we found no evidence for enriched association at coding variants only (exon (observed $\mathrm{N}_{\mathrm{P}<P \text { threshold }} / \mathrm{N}_{\text {total }}=17 / 292 ; P_{\text {enrichment }}=$ 0.41 at $\left.P_{\text {threshold }}=0.05\right)$, nonsynonymous $(11 / 152$; $\left.P_{\text {enrichment }}=0.18\right)$, and synonymous $\left(9 / 177 ; P_{\text {enrichment }}=\right.$ 0.99)) (Figure 2).

In the second analysis, we performed gene-based analysis of rare coding variant (MAF $<5 \%$ ) using nonburden tests (optimal sequence kernel association test (SKATO)) [26], burden tests (SCORE-seq) [28], and weighted tests with SIFT [29], PolyPhen2 [30], and CAROL [31] scores for the functional effects of the variants. A total of 17 genes had a nominal burden signal of association $(P<0.05)$, most of which had two or more nonsynonymous rare variants, although they did not reach the threshold for significance after Bonferroni correction $\left(P<1.2 \times 10^{-4}\right)$ (Table 2, Figure S5 in Additional file 1). For VSTM1, a top gene driven by the gene-based test, we further validated eight rare variants in VSTM1 using Sanger sequencing with the same samples that were heterozygous for any of those variants in the initial sequencing stage; 29 of 31 samples were validated as heterozygous (false-positive rate $=$ $6.45 \%(2 / 31))$. The following analysis using only these validated samples showed that a set of the validated seven nonsynonymous variants of VSTM1 conferred a protective role in RA $\left(P=4.55 \times 10^{-3}\right.$ in SKAT-O, $P=7.80 \times 10^{-4}$ in SCORE-seq). The four variants of VSTM1 were primarily within the immunoglobulin-like domain among the coding regions. The two variants, $\mathrm{A} 33 \mathrm{~T}$ at the domain and D122N closed to the domain, were thought to be deleterious 


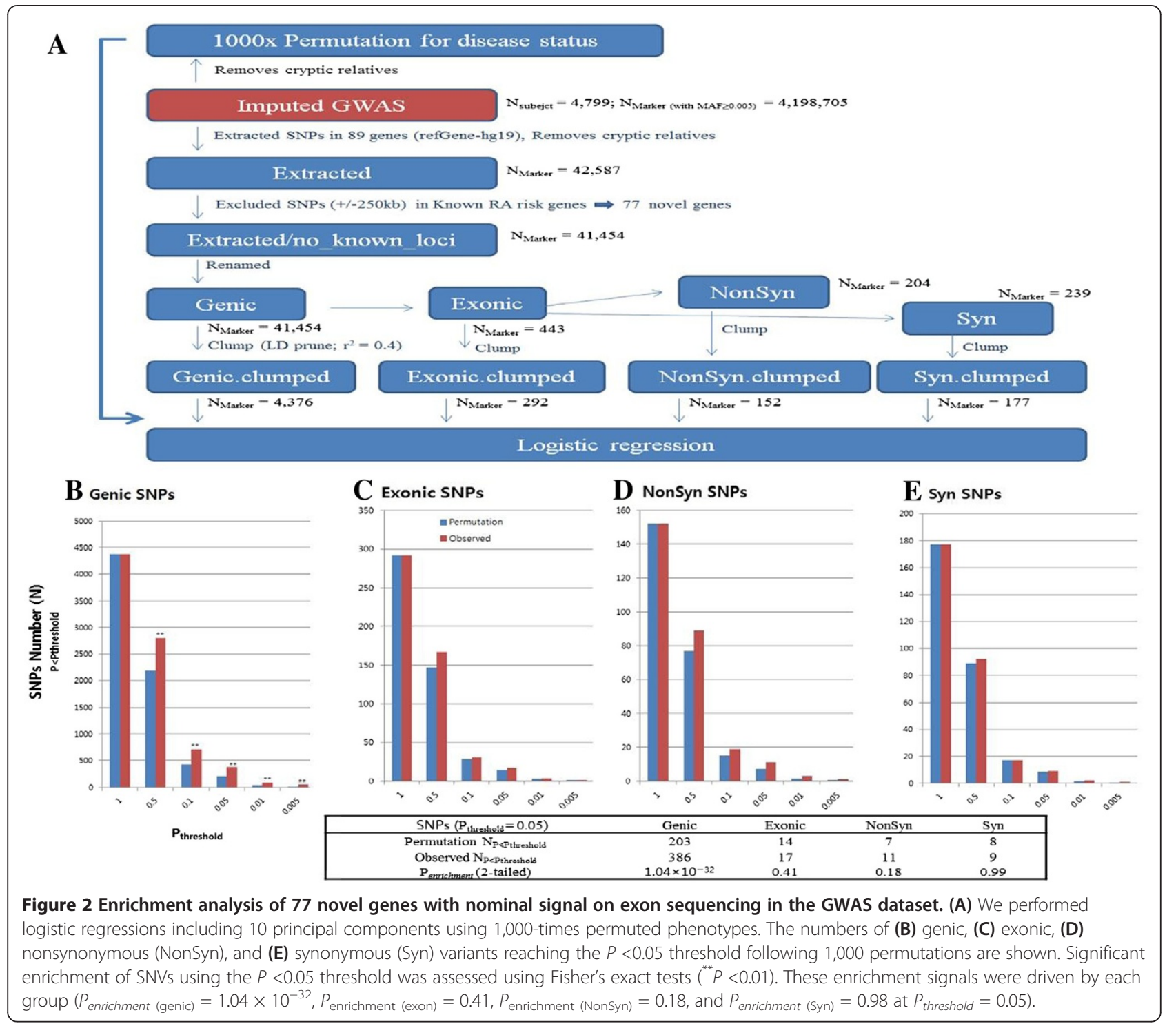

variants by PolyPhen2, suggesting that these may have a functionally protective role in RA (Figure 3 ).

In the third analysis, we conducted a pathway enrichment analysis of coding variants (nonsynonymous and synonymous) within 335 novel genes using Ontology and KEGG, which were obtained after excluding the known RA risk loci $(+/-250 \mathrm{~kb})$ from the initial 398 genes in NGS. In this analysis of both common and rare variants, we observed weak but significant evidence of overall enrichment of coding SNVs $\left(P_{\text {enrichment (nonsynonymous) }}=8.55 \times 10^{-4}\right.$ and $P_{\text {enrichment (synonymous) }}=0.166$ at $\left.P_{\text {threshold }}=0.05\right)($ data not shown) for the 335 genes. However, in the analysis for each pathway, we did not identify any pathway in which a significant enrichment for coding variants for RA existed at $P_{\text {threshold }}=0.05$.

\section{Discussion}

This study does not support our hypothesis that the substantial proportion of missing heritability for RA can be inferred from rare coding variants. Among the 10,588 candidate variants of 398 genes analyzed in a cohort of 1,217 RA cases and 717 controls, 13 single nonsynonymous variants showed only nominal significance with a $P$ value less than 0.01 . Several genes found in the genebased analysis also showed only weak association with RA.

Strikingly, this lack of a significant effect is consistent with that observed by Diogo et al. [17] in Caucasian population, in which most of the 25 candidate genes subjected to deep exon sequencing did not harbor rare coding variants contributing to risk of RA despite some evidence of accumulation of rare missense variants in 
Table 2 Gene-based tests of rare nonsynonymous variants in RA

\begin{tabular}{|c|c|c|c|c|}
\hline \multirow[t]{3}{*}{ GENE } & \multirow[t]{3}{*}{ Chr } & \multicolumn{3}{|c|}{ Gene-based test ${ }^{*}$} \\
\hline & & \multirow[t]{2}{*}{$\mathrm{N}_{\text {marker }}$} & \multirow{2}{*}{$\begin{array}{l}\text { SKAT-O } \\
\text { (nonburden test) } \\
P \text { value }\end{array}$} & \multirow{2}{*}{$\begin{array}{l}\text { SCORE_seq } \\
\text { (burden test) } \\
P \text { value }\end{array}$} \\
\hline & & & & \\
\hline VSTM1 & 19 & 7 & $4.55 \times 10^{-3}$ & $7.80 \times 10^{-4}$ \\
\hline KPRP & 1 & 8 & $6.38 \times 10^{-3}$ & $6.51 \times 10^{-3}$ \\
\hline C6orf99 & 6 & 5 & 0.05155 & 0.01669 \\
\hline PARD3 & 10 & 21 & 0.14496 & 0.01887 \\
\hline PYGL & 14 & 10 & 0.02287 & 0.02057 \\
\hline ARHGAP26 & 5 & 9 & 0.01939 & 0.02114 \\
\hline NCF2 & 1 & 8 & 0.02574 & 0.02159 \\
\hline CCR6 & 6 & 7 & 0.01131 & 0.02776 \\
\hline TRAF6 & 11 & 8 & 0.04621 & 0.02876 \\
\hline GRIN2B & 12 & 6 & 0.20806 & 0.02966 \\
\hline SNTB1 & 8 & 6 & 0.00987 & 0.03395 \\
\hline PTCD3 & 2 & 11 & 0.14462 & 0.03772 \\
\hline CA8 & 8 & 3 & 0.17982 & 0.03792 \\
\hline NRXN3 & 14 & 8 & 0.12536 & 0.03905 \\
\hline CPEB4 & 5 & 7 & 0.05104 & 0.04010 \\
\hline CTNNA3 & 10 & 16 & 0.10312 & 0.04079 \\
\hline KRT24 & 17 & 5 & 0.02866 & 0.04837 \\
\hline
\end{tabular}

"We defined rare nonsynonymous variants as MAF $<5 \%$ in both cases and controls. We selected 347 genes with two or more rare nonsynonymous variants for gene-based tests. RA, rheumatoid arthritis; Chr, chromosome; $\mathrm{N}_{\text {marker, }}$ number of rare nonsynonymous variants for each gene. gene-based test. Although 16 genes were overlapped between our Korean study and the Caucasian study [17], we could not find any significant single coding variant or gene that was shared in both ethnic groups. Taken together, rare functional variants may have very weak contribution to development of RA.

Besides, recent large-scale sequencing studies of six common autoimmune diseases (autoimmune thyroid disease, Crohn's disease, celiac disease, psoriasis, multiple sclerosis, and type 1 diabetes) showed a negligible impact of rare autoimmune-locus coding variants on unexplained heritability $(<3 \%)[34]$.

A possible reason for this negative finding may be the limited number of targeted genes that were sequenced, which were 398 genes in the current study. Rare coding variants of the remaining genes across whole genome could participate in the missing genetic contribution to $\mathrm{RA}$. The other potential reason may be genetic heterogeneity for RA, in which each individual or small subset of RA may have their particular rare causal variants. The current study revealed a lot of examples in which a specific rare variant was observed in only one or two individuals among 1,934 subjects. To discover these lots of 'private' causal variants that are susceptible only in small subsets of RA patients, deep sequencing of whole exome from very large RA cases, approximately thousands of individuals, would be required.

VSTM1, a top signal gene driven by a gene-based test, is a glycoprotein primarily expressed in immune tissues, which can promote the differentiation and activation of Th17 cells [35]. In addition, two variants of VSTM1 (A33T, $\mathrm{D} 122 \mathrm{~N}$ ) found in the current study were deleterious

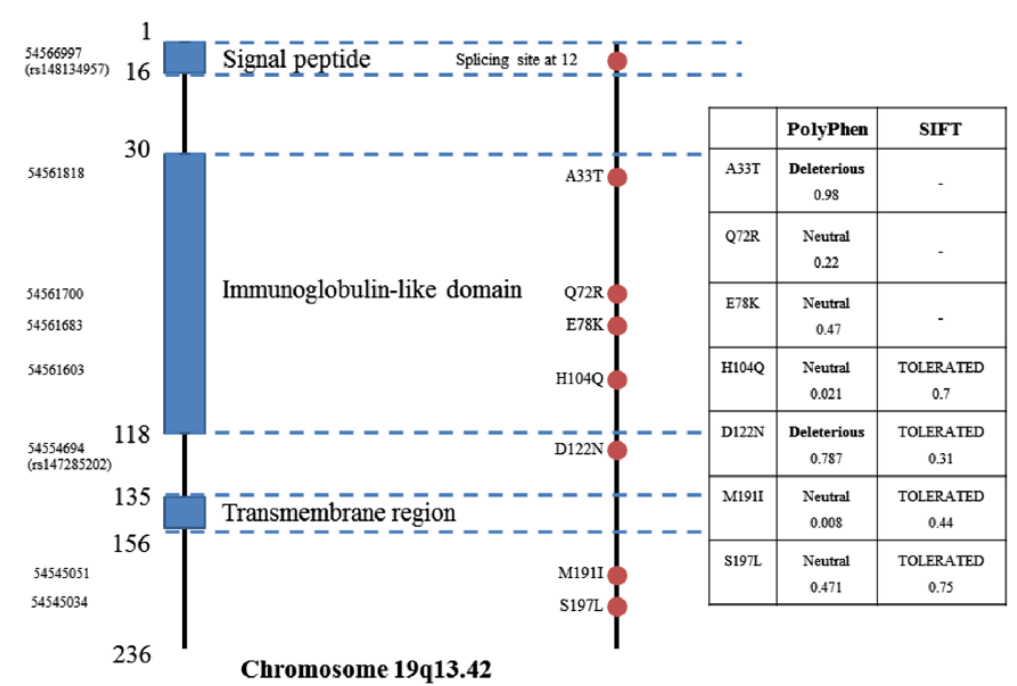

Figure 3 Rare variants of VSTM1 identified by exon sequencing. The seven nonsynonymous variants of VSTM1 that were validated by the Sanger sequencing method were primarily singletons driven from controls except for A33T (RA $(n=3)$, control $(n=5)$ ). The four nonsynonymous variants of VSTM1 lie within the coding regions of the immunoglobulin-like domain. 
variants by PolyPhen2. Therefore, it is certainly worth replicating these variants or performing deep sequencing of the entire VSTM1 gene from an independent larger population, especially in Caucasians.

There are several limitations of this study. First, we performed a targeted exon sequencing study, which tends to generate more biased data than whole-exome or whole-genome sequencing studies. Additionally, we did not attempt to validate all rare variants identified by alternative methods, but rather performed it only for selected variants such as Sanger sequencing of rare nonsynonymous variants of VSTM1 and TaqMan genotyping of 37 variants from 200 samples. Finally, we included approximately 2,000 subjects for sequencing, which might not be enough of a sample size to discover rare variants. Consequently, this lack of power may lead most of the analysis in the study, such as the single-variant association analysis, gene-based tests, and enrichment tests, to be less significant with weak association.

However, to our knowledge, this study represents the largest sequencing study that evaluated the largest number of candidate genes with the largest case controls for RA until now. Despite negative findings, further replication of the possible single variants or rare variants in the study will be of some interest.

\section{Conclusions}

We were unable to identify rare coding variants with large effect of 398 targeted genes. Despite much anticipation regarding missing heritability, our study raises skepticism about next-generation sequencing of targeted genes in order to discover rare variants with large effect for complex traits like RA. With the advance of genetic technology such as capturing, sequencing of targeted genes, and whole-exome or genome sequencing with a lot of subjects could define more details about the genetic architecture of $\mathrm{RA}$ in future.

\section{Additional file}

Additional file 1: Table S1. Targeted gene coverage rate (percentage) of coding variants sequenced within 398 genes via exon sequencing. Table S2. Quality metrics for exon sequencing of 398 targeted genes. Table S3. Concordance of targeted exon sequencing (NGS) with other datasets (GWAS, iCHIP), and validation data (Taqman). Table S4. Single-variant test: results for exon sequencing of nonsynonymous variants $(P<0.01)$. Table S5. Meta-analysis of single-association tests for coding variants (NGS + GWAS + iCHIP). Figure S1. A multifaceted approach in selecting target genes for resequencing in RA. Figure S2. Targeted exon sequencing pipeline. Figure S3. Principle component analysis for targeted exon sequencing. Figure $\mathbf{S 4}$. High-quality variants identified by targeted exon sequencing. Figure $\mathbf{S 5}$. Gene-based analysis of rare nonsynonymous variants in RA.

\section{Abbreviations}

Chr: chromosome; db: database; GWAS: genome-wide association studies; HLA: human leukocyte antigen; HWE: Hardy-Weinberg equilibrium;
iCHIP: immunochip; LD: linkage disequilibrium; MAF: minor allele frequency; MHC: major histocompatibility complex; NGS: next-generation sequencing; OR: odds ratio; PC: principal component; RA: rheumatoid arthritis; SD: standard deviation; SEM: standard error of the mean; SNP: single nucleotide polymorphism; SNV: single nucleotide variant.

\section{Competing interests}

All authors declare that they have no competing interests.

\section{Authors' contributions}

SYB contributed to the data collection and analysis, interpretation of data, manuscript writing, critical revision, and final approval of manuscript. YJN contributed to the data analysis, critical revision, and final approval of manuscript. KK contributed to the data analysis, was involved in drafting the manuscript, critical revision, and final approval of manuscript. YBJ contributed to the data collection, critical revision, and final approval of manuscript. YP contributed to the data analysis, critical revision, and final approval of manuscript. $J L$ contributed to the data analysis, critical revision, and final approval of manuscript. SYL contributed to the data analysis, critical revision, and final approval of manuscript. AAA contributed to the data analysis, critical revision, and final approval of manuscript. JJ contributed to the data analysis, critical revision, and final approval of manuscript. HR contributed to the data analysis, critical revision, and final approval of manuscript. JYL contributed to the data interpretation, critical revision, and final approval of manuscript. BGH contributed to the data interpretation, critical revision, and final approval of manuscript. SMA contributed to the study design, critical revision, and final approval of manuscript. SW contributed to the data analysis, critical revision, and final approval of manuscript. HSL contributed to the interpretation of data, manuscript writing, critical revision, and final approval of manuscript. SCB contributed to the data collection and analysis, interpretation of data, manuscript writing, critical revision, and final approval of manuscript. SYB, $\mathrm{HSL}$, and SCB have full access to all data in this study and take responsibility for the integrity and analysis of data. All authors read and approved the final manuscript.

\section{Acknowledgements}

The authors are grateful to their colleagues for assistance with sample preparation, data collection and biospecimens from the Korean Biobank Project, which is supported by the Korea Center for Disease Control and Prevention at the Korea National Institute of Health. This study was supported by a grant from the Korea Healthcare Technology R\&D Project [A111218-11-GM01, HI12C1834 (A121983)], Ministry for Health and Welfare, Republic of Korea.

\section{Author details}

'Department of Rheumatology, Hanyang University Hospital for Rheumatic Diseases, 220 Wangsimni-ro, Seoul 133-792, Republic of Korea. ${ }^{2}$ Department of Applied Statistics, Chung-Ang University, 29 Heukseong-no, Seoul 156-755, Republic of Korea. ${ }^{3}$ Department of Oncology, Asan Medical Center, 88 Olympic-ro 43-gil, Seoul 138-736, Republic of Korea. ${ }^{4}$ Bioinfomatics Center, Macrogen Inc., 60-24, Gasan-dong, Seoul 153-023, Republic of Korea. ${ }^{5}$ Center for Genome Science, Korea National Institute of Health, Osong Health Technology, 187 Osongsaengmyeong 2-ro, Chungcheongbuk-do 363-700, Republic of Korea. ${ }^{6}$ Department of Biomedical Informatics, Asan Medical Center, 88 Olympic-ro 43-gil, Seoul 138-736, Republic of Korea. ${ }^{7}$ Public Health Science, Graduate School of Public Health, Seoul National University, 1 Kwanak-ro Kwanak-gu, Seoul 151-742, Republic of Korea.

Received: 22 March 2014 Accepted: 29 August 2014

Published online: 30 September 2014

\section{References}

1. MacGregor AJ, Snieder H, Rigby AS, Koskenvuo M, Kaprio J, Aho K, Silman AJ: Characterizing the quantitative genetic contribution to rheumatoid arthritis using data from twins. Arthritis Rheum 2000, 43:30-37.

2. Scott DL, Wolfe F, Huizinga TW: Rheumatoid arthritis. Lancet 2010, 376:1094-1108.

3. Stahl EA, Raychaudhuri S, Remmers EF, Xie G, Eyre S, Thomson BP, Li Y, Kurreeman FAS, Zhernakova A, Hinks A, Guiducci C, Chen R, Alfredsson L, Amos Cl, Ardlie KG, Barton A, Bowes J, Brouwer E, Burtt NP, Catanese JJ, Coblyn J, Coenen MJH, Costenbader KH, Criswell LA, Crusius JBA, Cui J, 
de Bakker PIW, De Jager PL, Ding B, Emery P, et al: Genome-wide association study meta-analysis identifies seven new rheumatoid arthritis risk loci. Nat Genet 2010, 42:508-514.

4. Freudenberg J, Lee HS, Han BG, Shin HD, Kang YM, Sung YK, Shim SC, Choi CB, Lee AT, Gregersen PK, Bae SC: Genome-wide association study of rheumatoid arthritis in Koreans: population-specific loci as well as overlap with European susceptibility loci. Arthritis Rheum 2011, 63:884-893.

5. Zhernakova A, Stahl EA, Trynka G, Raychaudhuri S, Festen EA, Franke L, Westra HJ, Fehrmann RS, Kurreeman FA, Thomson B, Gupta N, Romanos J, McManus R, Ryan AW, Turner G, Brouwer E, Posthumus MD, Remmers EF, Tucci F, Toes R, Grandone E, Mazzilli MC, Rybak A, Cukrowska B, Coenen MJ, Radstake TR, van Riel PL, Li Y, de Bakker PI, Gregersen PK, et al: Meta-analysis of genome-wide association studies in celiac disease and rheumatoid arthritis identifies fourteen non-HLA shared loci. PLoS Genet 2011, 7:e1002004.

6. McAllister K, Eyre S, Orozco G: Genetics of rheumatoid arthritis: GWAS and beyond. OA Rheumatol Res Rev 2011, 3:31-46.

7. Eyre S, Bowes J, Diogo D, Lee A, Barton A, Martin P, Zhernakova A, Stahl E, Viatte S, McAllister K, Amos Cl, Padyukov L, Toes RE, Huizinga TW Wijmenga C, Trynka G, Franke L, Westra HJ, Alfredsson L, Hu X, Sandor C, de Bakker PI, Davila S, Khor CC, Heng KK, Andrews R, Edkins S, Hunt SE, Langford C, Symmons D, et al: High-density genetic mapping identifies new susceptibility loci for rheumatoid arthritis. Nat Genet 2012, 44:1336-1340.

8. Kim K, Bang SY, Lee HS, Cho SK, Choi CB, Sung YK, Kim TH, Jun JB, Yoo DH Kang YM, Kim SK, Suh CH, Shim SC, Lee SS, Lee J, Chung WT, Choe JY, Shin HD, Lee JY, Han BG, Nath SK, Eyre S, Bowes J, Pappas DA, Kremer JM, Gonzalez-Gay MA, Rodriguez-Rodriguez L, Arlestig L, Okada Y, Diogo D, et al: High-density genotyping of immune loci in Koreans and Europeans identifies eight new rheumatoid arthritis risk loci. Ann Rheum Dis 2014, [Epub ahead of print].

9. Raychaudhuri S: Recent advances in the genetics of rheumatoid arthritis Curr Opin Rheumatol 2010, 22:109-118.

10. Raychaudhuri S, Sandor C, Stahl EA, Freudenberg J, Lee H-S, Jia X, Alfredsson L, Padyukov L, Klareskog L, Worthington J, Siminovitch KA, Bae S-C, Plenge RM, Gregersen PK, de Bakker PIW: Five amino acids in three HLA proteins explain most of the association between MHC and seropositive rheumatoid arthritis. Nat Genet 2012, 44:291-296.

11. Stahl EA, Wegmann D, Trynka G, Gutierrez-Achury J, Do R, Voight BF, Kraft P, Chen R, Kallberg HJ, Kurreeman FA, Diabetes Genetics R, Meta-analysis C, Myocardial Infarction Genetics C, Kathiresan S, Wijmenga C, Gregersen PK, Alfredsson L, Siminovitch KA, Worthington J, de Bakker PI, Raychaudhuri S, Plenge RM: Bayesian inference analyses of the polygenic architecture of rheumatoid arthritis. Nat Genet 2012, 44:483-489.

12. Viatte S, Plant D, Raychaudhuri S: Genetics and epigenetics of rheumatoid arthritis. Nat Rev Rheumatol 2013, 9:141-153.

13. Rivas MA, Beaudoin M, Gardet A, Stevens C, Sharma Y, Zhang CK, Boucher G, Ripke S, Ellinghaus D, Burtt N, Fennell T, Kirby A, Latiano A, Goyette P, Green T, Halfvarson J, Haritunians T, Korn JM, Kuruvilla F, Lagace C, Neale B, Lo KS, Schumm P, Torkvist L, Dubinsky MC, Brant SR, Silverberg MS, Duerr RH, Altshuler D, Gabriel S, et al: Deep resequencing of GWAS loci identifies independent rare variants associated with inflammatory bowel disease. Nat Genet 2011, 43:1066-1073.

14. Nejentsev S, Walker N, Riches D, Egholm M, Todd JA: Rare variants of IFIH1, a gene implicated in antiviral responses, protect against type 1 diabetes. Science 2009, 324:387-389.

15. Momozawa Y, Mni M, Nakamura K, Coppieters W, Almer S, Amininejad L, Cleynen I, Colombel JF, de Rijk P, Dewit O, Finkel Y, Gassull MA, Goossens D, Laukens D, Lemann M, Libioulle C, O'Morain C, Reenaers C, Rutgeerts P, Tysk C, Zelenika D, Lathrop M, Del-Favero J, Hugot JP, de Vos M, Franchimont D, Vermeire $\mathrm{S}$, Louis $\mathrm{E}$, Georges M: Resequencing of positional candidates identifies low frequency IL23R coding variants protecting against inflammatory bowel disease. Nat Genet 2011, 43:43-47.

16. Bonnefond A, Clement N, Fawcett K, Yengo L, Vaillant E, Guillaume JL, Dechaume A, Payne F, Roussel R, Czernichow S, Hercberg S, Hadjadj S, Balkau B, Marre M, Lantieri O, Langenberg C, Bouatia-Naji N, Charpentier G, Vaxillaire M, Rocheleau G, Wareham NJ, Sladek R, McCarthy MI, Dina C, Barroso I, Jockers R, Froguel P: Rare MTNR1B variants impairing melatonin receptor 1B function contribute to type 2 diabetes. Nat Genet 2012, 44:1297-1301.
17. Diogo D, Kurreeman F, Stahl Eli A, Liao Katherine P, Gupta N, Greenberg Jeffrey D, Rivas Manuel A, Hickey B, Flannick J, Thomson B, Guiducci C, Ripke S, Adzhubey I, Barton A, Kremer Joel M, Alfredsson L, Sunyaev S, Martin J, Zhernakova A, Bowes J, Eyre S, Siminovitch Katherine A, Gregersen Peter K, Worthington J, Klareskog L, Padyukov L, Raychaudhuri S, Plenge Robert M: Rare, low-frequency, and common variants in the protein-coding sequence of biological candidate genes from GWASs contribute to risk of rheumatoid arthritis. Am J Hum Genet 2013, 92:15-27.

18. Arnett FC, Edworthy SM, Bloch DA, McShane DJ, Fries JF, Cooper NS, Healey LA, Kaplan SR, Liang MH, Luthra HS: The American Rheumatism Association 1987 revised criteria for the classification of rheumatoid arthritis. Arthritis Rheum 1988, 31:315-324

19. Okada Y, Terao C, Ikari K, Kochi Y, Ohmura K, Suzuki A, Kawaguchi T, Stahl EA, Kurreeman FA, Nishida N, Ohmiya H, Myouzen K, Takahashi M, Sawada T, Nishioka Y, Yukioka M, Matsubara T, Wakitani S, Teshima R, Tohma S, Takasugi K, Shimada K, Murasawa A, Honjo S, Matsuo K, Tanaka H, Tajima K, Suzuki T, Iwamoto T, Kawamura Y, et al: Meta-analysis identifies nine new loci associated with rheumatoid arthritis in the Japanese population. Nat Genet 2012, 44:511-516.

20. Lee HS, Kim T, Bang SY, Na YJ, Kim I, Kim K, Kim JH, Chung YJ, Shin HD, Kang YM, Shim SC, Suh CH, Park YB, Kim JS, Kang C, Bae SC: Ethnic specificity of lupus-associated loci identified in a genome-wide association study in Korean women. Ann Rheum Dis 2014, 73:1240-1245.

21. Bult CJ, Eppig JT, Kadin JA, Richardson JE, Blake JA: The Mouse Genome Database (MGD): mouse biology and model systems. Nucleic Acids Res 2008, 36:D724-D728.

22. Li H, Durbin R: Fast and accurate long-read alignment with BurrowsWheeler transform. Bioinformatics 2010, 26:589-595.

23. Li H, Handsaker B, Wysoker A, Fennell T, Ruan J, Homer N, Marth G, Abecasis G, Durbin R: The sequence alignment/map format and SAMtools. Bioinformatics 2009, 25:2078-2079.

24. Do R, Kathiresan S, Abecasis GR: Exome sequencing and complex disease: practical aspects of rare variant association studies. Hum Mol Genet 2012, 21:R1-R9.

25. Purcell S, Neale B, Todd-Brown K, Thomas L, Ferreira MA, Bender D, Maller J, Sklar P, de Bakker PI, Daly MJ, Sham PC: PLINK: a tool set for wholegenome association and population-based linkage analyses. Am J Hum Genet 2007, 81:559-575.

26. Lee S, Emond MJ, Bamshad MJ, Barnes KC, Rieder MJ, Nickerson DA Christiani DC, Wurfel Mark M, Lin X: Optimal unified approach for rare-variant association testing with application to small-sample case-control whole-exome sequencing studies. Am J Hum Genet 2012, 91:224-237

27. Neale BM, Rivas MA, Voight BF, Altshuler D, Devlin B, Orho-Melander M, Kathiresan S, Purcell SM, Roeder K, Daly MJ: Testing for an unusual distribution of rare variants. PLOS Genet 2011, 7:e1001322.

28. Lin D-Y, Tang ZZ: A general framework for detecting disease associations with rare variants in sequencing studies. Am J Hum Genet 2011, 89:354-367

29. Sim NL, Kumar P, Hu J, Henikoff S, Schneider G, Ng PC: SIFT web server: predicting effects of amino acid substitutions on proteins. Nucleic Acids Res 2012, 40:W452-W457.

30. Adzhubei IA, Schmidt S, Peshkin L, Ramensky VE, Gerasimova A, Bork P, Kondrashov AS, Sunyaev SR: A method and server for predicting damaging missense mutations. Nat Methods 2010, 7:248-249.

31. Lopes MC, Joyce C, Ritchie GR, John SL, Cunningham F, Asimit J, Zeggini E: A combined functional annotation score for non-synonymous variants. Hum Hered 2012, 73:47-51

32. Liu Q, Guo Y, Li J, Long J, Zhang B, Shyr Y: Steps to ensure accuracy in genotype and SNP calling from Illumina sequencing data. BMC Genomics 2012, 13:S8

33. DePristo MA, Banks E, Poplin R, Garimella KV, Maguire JR, Hartl C, Philippakis AA del Angel G, Rivas MA, Hanna M, McKenna A, Fennell TJ, Kernytsky AM, Sivachenko AY, Cibulskis K, Gabriel SB, Altshuler D, Daly MJ: A framework for variation discovery and genotyping using next-generation DNA sequencing data. Nat Genet 2011, 43:491-498.

34. Hunt KA, Mistry V, Bockett NA, Ahmad T, Ban M, Barker JN, Barrett JC Blackburn H, Brand O, Burren O, Capon F, Compston A, Gough SCL, Jostins L, Kong Y, Lee JC, Lek M, MacArthur DG, Mansfield JC, Mathew CG, Mein CA, Mirza M, Nutland S, Onengut-Gumuscu S, Papouli E, Parkes M, Rich SS, 
Sawcer S, Satsangi J, Simmonds MJ, et al: Negligible impact of rare autoimmune-locus coding-region variants on missing heritability. Nature 2013, 498:232-235.

35. Guo X, Zhang Y, Wang P, Li T, Fu W, Mo X, Shi T, Zhang Z, Chen Y, Ma D,

Han W: VSTM1-v2, a novel soluble glycoprotein, promotes the

differentiation and activation of Th17 cells. Cell Immunol 2012, 278:136-142.

doi:10.1186/s13075-014-0447-7

Cite this article as: Bang et al.: Targeted exon sequencing fails to

identify rare coding variants with large effect in rheumatoid arthritis.

Arthritis Research \& Therapy 2014 16:447

\section{Submit your next manuscript to BioMed Central and take full advantage of:}

- Convenient online submission

- Thorough peer review

- No space constraints or color figure charges

- Immediate publication on acceptance

- Inclusion in PubMed, CAS, Scopus and Google Scholar

- Research which is freely available for redistribution 